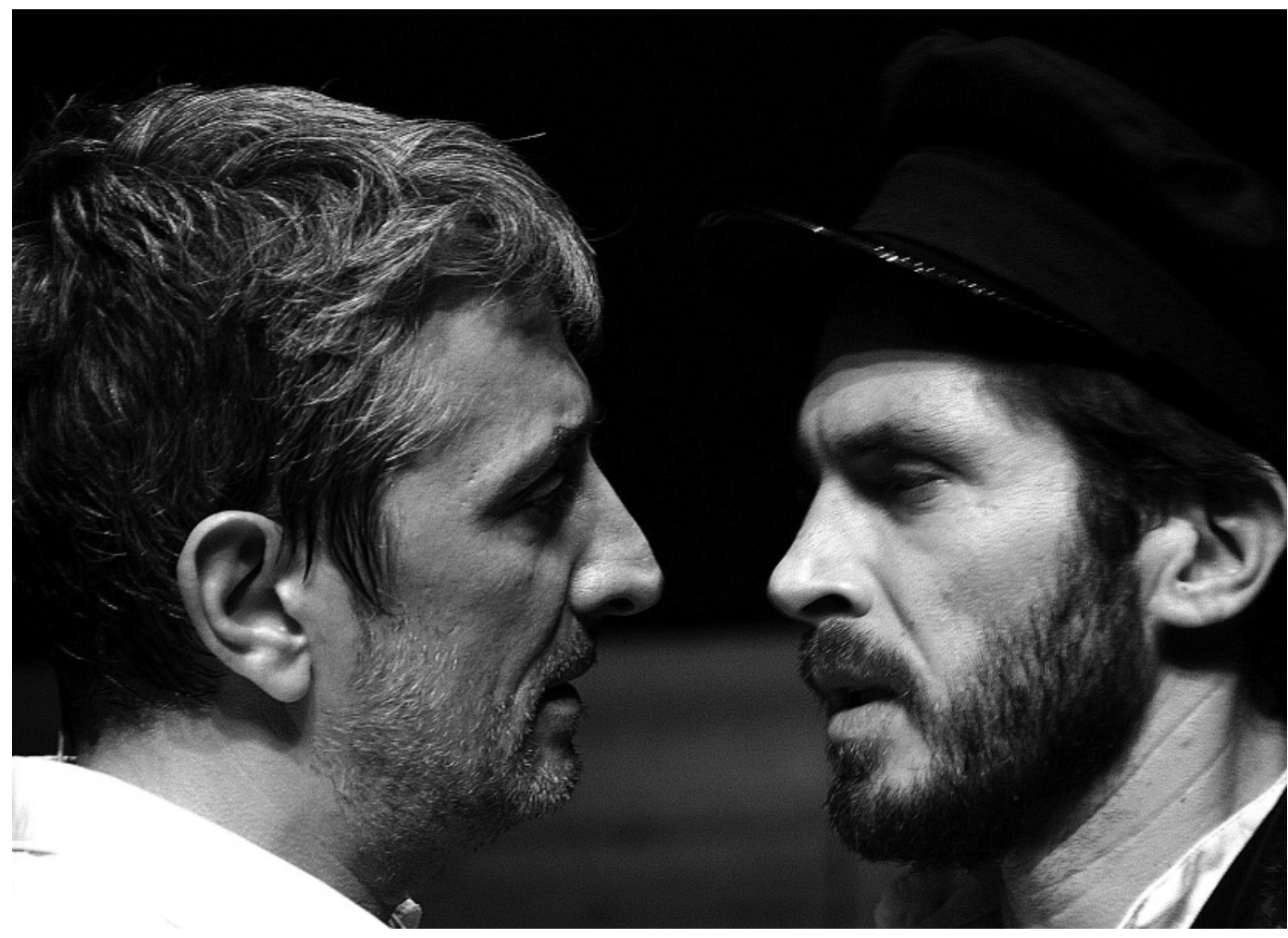

\title{
As razões da arte maior Puntila e o seu criado Matti
}

\author{
Maria Helena Serôdio
}

Titulo: O senhor Puntila e o seu criado Matti (1940). Autor: Bertolt Brecht. Versão: João Lourenço e Vera San Payo de Lemos. Dramaturgia: Vera San Payo de Lemos. Encenação e realização vídeo: João Lourenço. Música: Mazgani. Cenário: António Casimiro e João Lourenço. Figurinos: Bernardo Monteiro. Coreografia:Cláudia Nóvoa. Supervisão audiovisual:Aurélio Vasques. Luz: Melim Teixeira. Interpretação: Miguel Guilherme, Sérgio Praia, Sofia de Portugal, Rui Morisson, Francisco Pestana, Cristóvão Campos, Sara Cipriano, Mafalda Luis de Castro, Patricia André, Cátia Ribeiro, Carlos Malvarez e Carlos Pisco. Músicos: João Fernandez (guitarra e voz), Miguel Tapadas (Piano e acordeão), Vasco Sousa (Contrabaixo e baixo acústico). Produção: Novo Grupo/Teatro Aberto. Local e data de estreia: Teatro Aberto, Lisboa, 15 de Outubro de 2010.

Há uma sólida dimensão de saber - literário, cultural, artístico, social, humano - integrado nesta nova criação do Novo Grupo/Teatro Aberto que lhe garante uma respiração extraordinária. Converge com o conceito de "trabalho" que Brecht soube enunciar teoricamente e pôr em prática de forma fulgurante no teatro que, de forma inteligente, ousada e sensivel, foi criando. E essa dimensão do trabalho concita, naturalmente, a irritação - (a)social - de quem acha que tudo surge por obra de um só (seja ele artista, funcionário, cientista ou político) e se afadiga a "denunciar" - por exemplo no caso de Brecht - as "autorias" que o dramaturgo sonegou às mulheres com quem trabalhou na escrita de peças. E por aí se esquece - porque politicamente neste caso isso pode render - que o teatro é seguramente a arte mais colectiva que existe, quer entendendo-a na sua dimensão antropológica, quer reportando-a à prática cultural e social que em palco a configura e engrandece. E esquece ainda que, mesmo naquele que é o locus classicus da representação literária do individualismo burguês - o romance de Daniel Defoe,
Robinson Crusoe (1719) -, se regista que a sua vida solitária na ilha não prescindiu das ferramentas e outros despojos (resultantes do trabalho de muitos) que o herói pôde resgatar do barco afundado (para já não invocar o trabalho posterior do indígena Sexta-Feira que ele toma por criado).

É certo que esta peça de Brecht se inspirou numa outra - Princesa da serradura - da escritora e destacada intelectual finlandesa de esquerda Hella Wuolijoki, em cuja propriedade - Marlebäck - Brecht se acolheu com a familia e com a secretária Margareta Steffin no Verão de 1940, durante parte do seu exilio (tendo passado antes pela Dinamarca e Suécia). Escrita nos anos trinta, a peça de Hella W. era uma comédia popular que seguia os cânones convencionais e que acabou por ser refeita por intervenção de Brecht: primeiro, num trabalho conjunto com a própria Hella (que a queria apresentar a um concurso da Associação de Dramaturgos Finlandeses que, de resto, não ganhou); posteriormente, incorporando já questões políticas e opções estéticas claramente brechtianas que, mais tarde - quando politicamente the foi possivel fazê-lo ${ }^{1}-$, o levaram a
${ }^{1}$ Como podemos ler no como sempre, excelente - programa do espectáculo (p. 12), Brecht assina - de comum acordo com a escritora um contrato em que sera ela, com pseudónimo, que assinaria contratos desta peça enquanto ele estivesse inibido de o fazer na Alemanha, e quando peça tem a sua estreia mundial em 1948 em Zurique, com encenação de Brecht, quem a assina é Kurt Hirschfeld, uma vez que BB não possuí licença de trabalho na Suiça. 


\section{$<>$
Osenhor Puntila e o seu criado Matti, de Bertolt Brecht, enc. João Lourenço, Novo Grupo/ Teatro Aberto, 2010 (< Sofia de Portugal e Sérgio Praia; \\ $>$ Patrícia André, Sérgio Praia, Mafalda Luis de Castro e Sara Cipriano),}

fot. João Lourenço.

Na sua longa carreira de encenador contam-se as seguintes recriações das peças de Brecht: As espingardas da mãe Carrar (1975), 0 circulo de giz caucasiano (1976), Baal (1980) - quando

pela primeira vez se cruza com Vera San Payo de Lemos -, A boa pessoa de

Setzuan (1984), Ascensão e queda da cidade de Mahagony

Mãe Coragem e os seus

filhos (1986),

A ópera de três vinténs (1992 e 2005), Galileu (2006). Para informação mais pormenorizada ver na CETbase, do Centro de Estudos de Teatro, a sua

ficha individual: http://www.fl.ul.pt/CET

base/reports/client/

Report.htm?ObjType= Pessoa\&tobild = 369

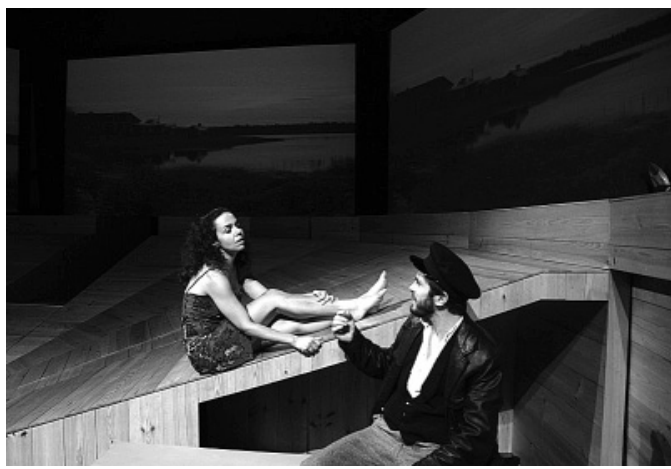

registar a peça como de sua autoria individual (apenas uma nota referia Hella Wuolijoki como "fonte", aspecto que a magoou, mas que não a impediu de com ele se reconciliar em Berlim, quando foi ver a peça encenada, em 1950). De facto, integrando algumas historietas e aspectos do enredo da obra de Hella W., a peça de Brecht é radicalmente outra coisa: ao nível da estrutura, passou dos "clássicos" 4 actos a 9 cenas; e, no que diz respeito à definição social e ideológica, substituiu a romântica ideia do engenheiro que se disfarça de motorista para estar perto de Eva - a filha de Puntila -, para a definição de um verdadeiro proletário que está consciente da sua origem social e revela uma invulgar clarividência política. E é justamente na análise impiedosa da oposição patrão vs assalariado - feita, aliás, com uma graça, leveza e ironia (não isenta de emoção) extraordinárias - que reside o fulgor maior desta representação.

Dois momentos fulcrais revelam-se determinantes nessa análise: a definição da marca ideológica do patrão de encontro a uma inversão do que se entende por "excentricidade" ou fora do seu "centro" social (numa explosão de graça e humanidade), e na brilhante cena da "praça de jorna" (no espectáculo referida ao termo menos marcado de "praça do trabalho"). No primeiro caso, é na embriaguez - quando está "fora de si" - que Puntila é amável e generoso, e considera estar "na plena posse das [suas] faculdades mentais" com o "domínio absoluto sobre todos os [seus] sentidos"; e é quando está sóbrio - ocupando o seu "lugar ideológico" - que Puntila, como ele próprio reconhece quando confraterniza com o criado/motorista, "[desce] pura e simplesmente ao nível do animal, da besta".

A "praça do trabalho" constitui um momento carismático do que pode ser o brechtianismo em teatro: tornando os espectadores figurantes - como eventuais trabalhadores que, ansiosos e amargurados, esperam ser contratados - e opondo as investidas do patrão, com todos os tiques do explorador impiedoso, aos comentários de profunda comiseração do criado/motorista. E é nesta combustão vibrátil de crueldade e solidariedade - entre o soco no estômago e a ternura de uma compaixão - que reconhecemos o valor artístico de Brecht e a sua admiráve recriação neste espectáculo.

De facto, nesta produção do Novo Grupo/ Teatro Aberto em torno do cómico Puntila "bipolar", há uma hábil conjunção de saberes já bem testados em palco: o do domínio da tradução e dramaturgia brechtianas (por Vera San Payo de Lemos), o da competência de pôr em cena Brecht (por parte de João Lourenço ${ }^{2}$ ), o do apurado domínio oficinal da construção de cenografias (de António Casimiro e João Lourenço), o da exuberância interpretativa de Miguel

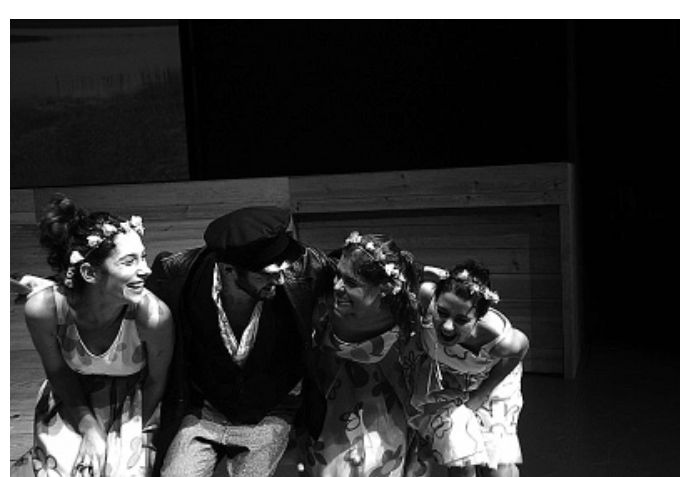

Guilherme, com um percurso teatral muito variado, e tão à-vontade na interpretação de textos clássicos, quanto na criação - em palco e na televisão - de figuras cómicas desde a mais elaborada sofisticação literária ao riso mais apalhaçado. Seria, porém, injusto não referir a afinação do trabalho cénico de todos os outros actores, com visíve destaque ainda para o brilho interpretativo de Sérgio Prata e de Sofia de Portugal. Cruza-se ainda com estes saberes teatrais o valor artístico incontestado (mesmo no plano internacional) do português-iraniano Mazgani que assina a música e que assegura, pelos instrumentistas João Fernandez (também cantor), Miguel Tapadas e Vasco Sousa, intervenções admiráveis ao longo do espectáculo.

Na montagem de todas estas competências - e por força de um projecto claro de teatro popular por parte de Brecht - o espectáculo em cena no Teatro Aberto tornouse um extraordinário êxito artístico. E não deixa de nos fazer recordar - aos que, por razões da vida mais longa, o terão visto - o que foi o êxito de 0 círculo de giz caucasiano, só que, curiosamente, em respirações políticas bem diversas: diferentemente do que pode ter sido, então, a sintonia com a afirmação das forças progressistas em 1976, é agora a vontade de perceber o que correu e corre mal quando se sonha igualizar a humanidade - num mundo em que o processo de produção opõe patrões a assalariados -, por mais bondade e generosidade que possam respirar as propostas políticas da intervenção militante de esquerda.

0 trabalho dramatúrgico levou a uma versão que diminuiu figuras e conversas, introduziu um poema e uma canção que Brecht escrevera noutros sítios, refez as falas das raparigas para se adequarem a canções (musicadas em jeito de "tango" finlandês), mas - acima de tudo permitiu a intromissão de uma outra forma musical que não a partitura de Paul Dessau. E, de facto, essa reinvenção revela-se de importância decisiva ao longo de todo o espectáculo, mas com uma coda final que é de uma elevação artística soberba e rara.

Na definição cenográfica, alia-se a referência quer à floresta finlandesa, quer à presença (e odor) das bétulas - que Brecht repetidamente invoca no seu diário - com a operacionalidade de um conjunto de estrados em madeira que, deslocados de forma eficiente, vão criando espaços de representação que ora celebram a ideia de chão onde se sentam ou dançam as figuras populares, ora se retraem para fazer surgir uma belíssima casa de sauna ou a sala da festa do noivado, ora ainda se redimensionam para figurarem uma espécie de anfiteatro que deixa - nos bordos laterais e do fundo do palco - espaço para aparecimentos e desaparecimentos fabulosos: são as 


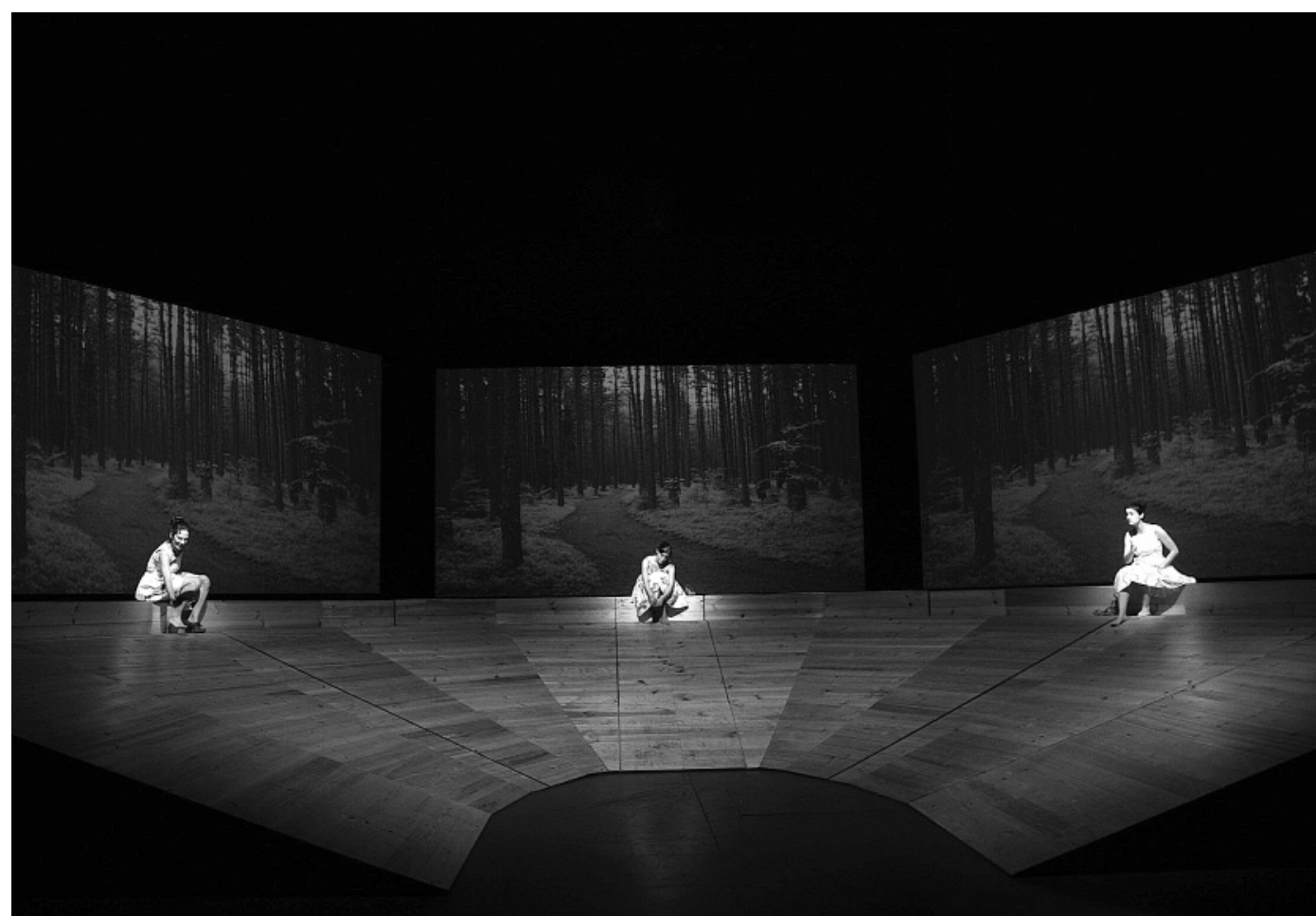

"noivas" de Puntila a saltarem - positivamente - para o "buraco" e a cena das muitas garrafas em grades (iluminadas de forma magnífica) no momento em que Puntila quer cortar definitivamente com a bebida, para se fixar no seu "centro" social e ideológico.

Com figurinos - de Bernardo Monteiro - desenhados com cuidado e respeitando a diversidade de "mundos" que passam naquele universo humano, o espectáculo oferece variações cromáticas curiosas (veja-se a subtil relação entre os vestidos das três "noivas" de Puntila, por exemplo), uma anotação às vezes mínima, mas cheia de sentido e valor - como é o caso do colete rosa do Adido -, uma variedade de vestidos de festa (vagamente relembrando os anos cinquenta), e uma composição interessante e de traço nítido para os figurinos de Puntila e do seu criado Matti.

Um outro aspecto a que João Lourenço nos vem habituando - o uso de projecções de imagens gravadas ou ao vivo - reaparece aqui de forma oportuna, criando um prolongamento de cena que ora raia a comicidade (no desastre de automóvel de Puntila), ora concita a nostalgia de um final em que o motorista abdica do seu lugar electivo naquela propriedade (e no coração de Eva) para ir à procura de um outro destino caminhando pela floresta que se "abre" no telão do fundo do palco. Pelo meio vemos ainda a operacionalidade das câmaras que captam ao vivo pormenores da cena ou da plateia, permitindo um convivio divertido de cada um com as imagens dos outros e de si mesmo. E esse jogo voyeurista prolonga-se numa outra cena fabulosa de inventividade, graça e impacto no público: como se se tratasse de teatro dentro do teatro, ou, mais rigorosamente, de "concurso televisivo" dentro do teatro, assistimos à admirável cena em que Eva quer demonstrar a sua capacidade de ocupar o lugar social da mulher de um trabalhador rural - com "bocas" do pai como "concentrate...", que é o que tantas vezes ouvimos nesses concursos. Pode soar insólito, mas a certa altura parecia também evocar - parodicamente - a célebre cena da Beatriz Costa a cantar "O chega, chega, chega, chega minha agulha", do filme A canção de Lisboa (1933, de Cottinelli Telmo), com o pai (António Silva) também a "torcer" pela "vitória" da filha.

Não falta ao espectáculo a respiração mais vasta de um espaço como a floresta em tempo de Verão, recuperando a cena essa atmosfera generosa de calor e cheiros, tudo incendiado pela alegria das raparigas e por imagens projectadas da paisagem finlandesa que pareciam transportar-nos a todos para fora deste Inverno que se aproxima. Tudo na cena convida a essa ebulição de vida e terá o seu picante na desobediência de Eva que, para desencorajar o pretendente, simula uma cena intima com Matti na sauna: um atrevimento que entra alegremente no enredo da comédia.

Outro aspecto decisivo para a qualidade deste espectáculo residiu no trabalho dos actores, desde os que definem os três papéis principais - Puntila, a filha e o criado - a todos quantos colaboraram nesta excepcional invenção teatral: Sara Cipriano, Mafalda Luis de Castro, Patricia André (um feliz e acertadíssimo trio de noivas), Francisco Pestana e Rui Morisson, (exímios como Pastor e Juiz, respectivamente), Cristóvão Campos (um Adido de uma graça e leveza fantásticas, como um "gafanhoto de fraque" ao som de "we have no bananas today" - que muito deve à coreografia de Cláudia Nóvoa), a que se somam as presenças eficientes de Carlos Pisco, Cátia Ribeiro e Carlos Malvarez.

Em tempo de sombrio recrudescimento do desemprego, da desarticulação de mecanismos de apoio social, da visivel dominação do capital financeiro especulativo (que obriga a que todos paguemos os erros e jogos a que o sector bancário se entregou), é bom voltar às interrogações brechtianas. Que aqui ressurgem com um ebuliente sabor teatral, conjugando o riso e a nostalgia, a inteligência e a emoção, a arte e a vida, e que bem podem ajudar a desfazer dúvidas quanto à actualidade de Brecht para nós "que viemos depois dele". 